\title{
Dear Colleagues:
}

According to the Journal's Editorial Board members policy, we are pleased to announce the incorporation of two new members: Dr. Hernán Rios and Dr. Ramiro Araya. We would like to give these new members a very warm welcome. At the same time we want to express our gratitude to Dr. Alfonso Oliva who served as a member of the Editorial Board for 19 years.

I would like to take the opportunity to elaborate a brief summary of what my role as Editor has meant to the journal since I was appointed in this position in 2006. One of the main goals achieved during this period was an increase in the amount of contributions received for publication.

In fact, the number of manuscripts submitted has increased from 110 to 162 in the period 2006 to 2008 . In parallel, the number of rejected contributions also followed the same trend increasing in the same period from 10 to 35 , in line with our policy of keeping the Journal quality to the highest possible ends.

Another aspect that has been positively improved is the time for publication, reaching an average time of 4.9 months. It is also noteworthy the great increase in the number of foreign contributions received, some of which keep up very well with the quality standards imposed by the Journal. Thus, in the last four years the number of foreign contributions has increased five times. There is also a constant effort to increase the impact index. Among other actions, the incorporation of invited reviews has been considered. During 2007 and 2008, five reviews have been published and we expect to increases this number as well as the collaborations in other areas of chemistry. Finally, I would like to thank to all the chemists community that has supported my work and I personally encourage them to send their contributions to our Journal.

\section{Dr. Carlos Díaz Valenzuela \\ E D I T O R}

